\title{
Mulheres em campanha: uma análise da distribuição de recursos financeiros nos estados brasileiros e o desempenho eleitoral das mulheres nas eleições de 2014
}

\author{
Women in campaign: an analysis of the distribution of financial resources in brazilian states and \\ the electoral performance of women in the 2014 elections
}

Maria Cecília Eduardo ${ }^{1}$

\begin{abstract}
Resumo
O financiamento de campanha tem sido citado com destaque como um dos fatores do baixo desempenho feminino na conquista de cargos eletivos. O presente artigo busca (i) analisar como se dá a distribuição dos recursos financeiros nos estados brasileiros na campanha eleitoral, para os cargos proporcionais federais, entre mulheres e homens, nas eleições de 2014. E em seguida, pretende (ii) verificar se há uma relação entre os recursos financeiros declarados e o desempenho das/os candidatas/os. Constatou-se que na grande maioria dos estados a distribuição dos recursos esteve concentrada nos candidatos homens. Além disso, verificou-se que nos estados em que as receitas das mulheres foram maiores ou mais próximas às dos homens, o desempenho eleitoral delas foi melhor do que o de seus pares masculinos.
\end{abstract}

Palavras-chave: Desempenho eleitoral. Gênero. Financiamento de campanhas. Eleições 2014. Câmara dos Deputados.

\begin{abstract}
Campaign funding has been singled out as one of the factors of low female performance in winning elective positions. This article aims to (i) analyze the distribution of financial resources in the Brazilian states in the electoral campaign to the federal proportional positions between women and men in the 2014 elections. And then, intends to (ii) check whether there is a relationship between the declared financial resources and the performance of the candidates. It was found that in the vast majority of states the distribution of resources was concentrated on male candidates. In addition, it was found that in states where women's incomes were higher or closer to men's, their electoral performance was better than that of their male counterparts.

Keywords: Election Performance. Gender. Campaign Financing. 2014 Elections. Chamber of Deputies.
\end{abstract}

\section{Introdução}

Há uma crescente compreensão de que a igualdade de gênero é um indicador de empoderamento individual e coletivo (KABEER, 1999; SEN, 2000). Tal concepção gradativamente se difunde entre atores e organizações, sendo finalmente absorvida por organismos multilaterais no

1 Doutoranda no Programa de Pós-Graduação em Ciência Política da Universidade Federal do Paraná. E-mail: celfisio@gmail.com 
plano internacional. Como exemplos, a igualdade de gênero é um dos 17 Objetivos de Desenvolvimento Sustentável, da Agenda 2030, da Organização das Nações Unidas (ONU, 2015), e o Banco Mundial dedicou seu Relatório sobre Desenvolvimento Mundial de 2012 ao tema Igualdade de Gênero e Desenvolvimento (BANCO MUNDIAL, 2011).

Ao mesmo tempo em que se torna um problema público e entra na agenda política, a superação da desigualdade entre homens e mulheres é um longo caminho e diferentes países apresentam desempenho bastante diverso em seu enfrentamento nos mais diferentes campos, como a economia, a educação e a vida familiar. A política é, no entanto, uma das esferas em que o tema se coloca de maneira mais sensível. Tanto que o desequilíbrio na participação de homens e mulheres nas esferas da política formal passou a ganhar, nas últimas duas décadas, atenção especial no mundo, fazendo com que essa temática ganhasse espaço no campo acadêmico, nos fóruns internacionais diversos, nos movimentos feministas e nos grupos de mulheres nas instâncias partidárias (SACCHET; SPECK, 2012a). Dentre os fatores apontados como determinantes para a manutenção dessa assimetria, dois deles são mostrados como principais: o sistema eleitoral brasileiro, mais especificamente o sistema proporcional de listas abertas, e o financiamento de campanha (ARAUJO, 2013).

Dito isso, o presente texto busca discorrer sobre a baixa presença feminina na política brasileira tendo como foco o financiamento de campanha. Este sendo apresentado segundo as Unidades Federativas brasileiras com o intuito de verificar a existência (ou não) de diferença no acesso feminino à Câmara dos Deputados entre elas. Muitos são os estudos que apontam o financiamento como um dos principais fatores para explicar o sucesso eleitoral daqueles que se elegem (SPECK, 2005; LEMOS; MARCELINO; PEDERIVA，2010; CERVI，2013; SPECK; MANCUSO, 2013; MANCUSO; FIGUEIREDO FILHO, 2014; MANCUSO, 2015; HOROCHOVSKI, et. al. 2016). Uma vez que é graças à captação de recursos que o desenvolvimento da campanha e a divulgação do candidato para os eleitores são possíveis.

Entendido o financiamento como um dos fatores primordiais para o sucesso eleitoral, busca-se verificar se há uma relação entre os recursos financeiros declarados e o desempenho dos candidatos nas eleições de 2014. Pergunta-se: em que medida a arrecadação entre mulheres e homens difere? Essas eventuais diferenças apresentam viés territorial, ou seja, estão mais concentradas em determinados estados brasileiros? E podem ser relacionadas aos desempenhos eleitorais femininos e masculinos? As hipóteses apresentadas são duas: acredita-se que (i) serão encontradas particularidades significativas na distribuição de recursos financeiros das candidatas e dos candidatos, estes possuindo uma maior concentração de recursos; e, (ii) essa diferença na 
distribuição afetará o desempenho eleitoral dos concorrentes, ou seja, candidatos/as com mais recursos terão um melhor desempenho.

A proposta de um estudo sobre gênero ${ }^{2}$ e financiamento já foi abordada em outros trabalhos, porém, dois pontos devem ser levantados. O primeiro é que a investigação dessas duas temáticas ainda é pouco explorada. Compreende-se que as pesquisas brasileiras têm tratado o assunto financiamento eleitoral a partir de um foco na questão da corrupção, sendo poucos os estudos que enfocam de forma sistemática as consequências de tal relação para o princípio da igualdade política e o seu impacto sobre a inclusão de homens e mulheres no processo de tomada de decisão política (SACCHET; SPECK, 2012b; ZOVATTO, 2005; GARCIA, 2004). Sendo assim, esta pesquisa visa contribuir para o arcabouço teórico dos estudos sobre gênero, mais especificamente sobre mulheres na política. O segundo é que a proposta aqui feita difere-se das demais por trazer o panorama geral dos recursos declarados e dos votos obtidos nas eleições de 2014, para o cargo de deputado federal, com o intuito de dar continuidade aos estudos sobre a temática realizados em outras eleições. O foco é colocado na Câmara dos Deputados, uma vez que, em geral, é este o nível tratado pela literatura aqui utilizada.

O trabalho divide-se em quatro tópicos. O primeiro consiste em uma revisão bibliográfica dos temas aqui trabalhados e está divido em tópicos que abordam a questão da (baixa) presença feminina na política, apresentando um panorama atual da participação política feminina e a implementação das cotas partidárias para as mulheres no sistema eleitoral brasileiro. No segundo, tem-se a abordagem dos temas desempenho eleitoral e financiamento de campanha no Brasil, trazendo uma breve discussão do papel dos recursos financeiros nos pleitos eleitorais. Com o terceiro capítulo, explana-se metodologia adotada na pesquisa, com a explicação dos procedimentos estatísticos escolhidos, bem como a apresentação e a análise dos dados coletados. Por fim, o trabalho termina com a sistematização dos principais achados e as colocações pertinentes à pesquisa.

\section{Gênero e política}

Todo o processo de entrada da mulher na política vem sendo marcado por várias dificuldades que vão desde a falta de recursos, como tempo e dinheiro, até a persistência de

\footnotetext{
${ }^{2}$ A presente pesquisa limita a variável gênero ao sexo de quem compete: feminino ou masculino, informação que consta no site do Tribunal Superior Eleitoral (TSE).
} 
paradigmas conservadores como, por exemplo, a ideia de que política não é coisa de mulher. Somase a isto o fato de que, como lembram Araújo et. al. (2002), o campo político já possuía suas regras, as quais foram estabelecidas e estruturadas segundo critérios, dinâmicas, valores e referenciais masculinos. Atualmente, não só no Brasil, mas em quase todo o mundo, o percentual de mulheres em cargos políticos eletivos é muito baixo ${ }^{3}$. Fato que mostra os limites do vigente sistema político, uma vez que, como apontam Dahl (1989) e Lijphart (1999), cânones da teoria democrática, a participação de diferentes grupos no processo decisório é um importante elemento para o desenvolvimento democrático.

Dentro e fora dos partidos e das instituições políticas, a legitimidade adquirida pela perspectiva de necessidade do aumento da participação feminina nas esferas decisórias, juntamente com a pressão constante do movimento de mulheres, fizeram com que um número grande de países adotasse medidas afirmativas, as $\operatorname{cotas}^{4} \mathrm{em}$ particular, visando a alteração desse quadro. Segundo Sacchet (2013), essa medida é articulada a partir de um princípio de igualdade que vai além da ideia de direitos iguais no formato da lei. Ela é norteada pelo princípio que pressupõe a construção das condições necessárias para a efetivação da igualdade que, por sua vez, se consolida por meio de resultados e não somente condições iguais. Vemos que a igualdade formal tem se mostrado insuficiente na remoção de barreiras estruturais, explícitas e implícitas, que dificultam o acesso a certos grupos de serem selecionados como candidatos.

Contudo, a adoção das cotas partidárias, apesar do aumento quantitativo de candidaturas de mulheres ${ }^{5}$, tem se mostrado frágil como via de ampliação da participação política feminina. (MIGUEL, 2000; ARAÚJO, 2001, 2005; GROSSI; MIGUEL, 2001; ARAÚJO; ALVES, 2007). Vários são os fatores apontados para a falta de sucesso dessa política, dentre eles o sistema eleitoral adotado no Brasil aparece como um dos pontos centrais para o entendimento da baixa eficácia das cotas.

A literatura aponta que as cotas tendem a funcionar melhor em sistemas de representação proporcional com listas fechadas (MANSBRIDGE, 1999; MATLAND, 1998; MATLAND;

\footnotetext{
3 De acordo com a Inter Parliamentary Union (IPU), apenas $23 \%$ dos cargos legislativos mundiais são ocupados por mulheres. Lembrando que esta distribuição varia muito entre os países.

${ }^{4}$ No Brasil, em setembro de 1995, logo após a IV Conferência Mundial sobre a Mulher, ocorrida em Beijing, temos a aprovação da Lei n. ${ }^{\circ}$ 9.100, a qual, estabelecendo novas normas para a realização das eleições municipais de 1996 , determinou uma cota mínima de $20 \%$ para as mulheres .No ano de 1997 , essa mesma lei estende a medida para os demais cargos eleitos por voto proporcional e ainda altera o texto do artigo passando a haver não mais uma cota mínima para as mulheres, mas sim uma cota mínima de $30 \%$ e uma cota máxima de $70 \%$, para qualquer um dos sexos.

${ }^{5}$ Numericamente, a adoção da política de cotas tem mostrado resultados pois, no ano 2000, houve 70.321 mulheres concorrendo às Câmaras de Vereadores, sendo dessas 6.992 eleitas vereadoras. E nas eleições de 2014 (82 anos após a conquista do direito de voto das mulheres), temos 2.057 mulheres candidatas a deputadas federais $(30,45 \%)$ e 4.880 concorrendo ao cargo de deputada estadual $(30,4 \%)$.
} 
STUDLAR 1996; REYNOLDS, 1999; MOSER, 2001); quando há mandato de posição para as candidaturas, ou seja, quando existem regras que definem a posição dos candidatos de cada sexo nas listas, de acordo com percentual das cotas; e, além disso, quando a Justiça eleitoral penaliza de maneira efetiva os partidos que não cumpram a lei (HTUN; JONES 2002; SACCHET, 2008; JONES, 2009).

Duas outras variáveis também muito citadas como sendo favorecedoras de uma boa performance feminina nas eleições são a magnitude dos distritos (quanto maiores, melhores para as mulheres) e o perfil ideológico dos partidos (quanto mais à esquerda do espectro político, maior a tendência do partido de promover os direitos e a representação política das mulheres). Em relação à magnitude distrital, distritos maiores seriam mais favoráveis às mulheres pelos mesmos motivos apresentados sobre o sistema proporcional - maior disponibilidade de vagas gera menor disputa por elas (MATLAND; BROWN, 1992). Já a respeito da ideologia partidária, acredita-se que a ideologia mais igualitária dos partidos de esquerda faz com que esses tendam a reconhecer como legítimas as demandas pela promoção política das mulheres, selecionando mais candidatas e apoiando suas campanhas. Além disso, esses partidos teriam grupos internos de mulheres com maior potencial de pressão, por serem mais articulados e atuantes nas questões dos interesses e da representação política feminina (SACCHET, 2013, ARAÚJO, 2005; CAUL, 1997; LOVENDUSKI; NORRIS, 1993).

Expostas essas informações, nota-se que o sistema eleitoral brasileiro desfavorece a eleição de mulheres e grupos minoritários. Isso porque, num sistema de representação proporcional com listas abertas, as cadeiras conquistadas por partidos ou coligações são proporcionais ao total de votos que eles obtêm nas urnas e os candidatos eleitos são aqueles que individualmente conquistarem o maior número de votos no interior de cada partido ou coligação. Sendo assim, as eleições se constituem efetivamente em disputas entre candidatos, pois embora seja possível o eleitor votar na legenda, a maioria opta pelo voto personalizado, o que além de encarecer o pleito o transforma em uma competição desigual. Tal dinâmica eleitoral faz com que os recursos financeiros sejam um dos fatores mais cruciais na definição das chances de sucesso nas urnas (SACCHET, 2013, p. 95).

A mensuração do possível efeito do gasto de campanha sobre os resultados eleitorais têm sido um tema central na agenda de pesquisa da ciência política. (SAMUELS, 2001, 2002; SPECK, 2002, 2005; MANCUSO 2015; CERVI, 2013; MARCELINO, 2010; FIGUEIREDO FILHO, 2009) E no que diz respeito a isso, é importante ressaltar que os pleitos eleitorais nas democracias modernas acontecem em um contexto de desigual distribuição de recursos, sejam eles econômicos, 
simbólicos, culturais e sociais, entre aqueles que competem. Essa relação de desigualdade nas disputas eleitorais também é uma temática frequentemente abordada pelos estudos de ciência política.

Robert Dahl (2009) e Przeworski (1994), por exemplo, são autores que enfatizam a desigualdade de recursos em regimes políticos competitivos. Salienta-se aqui que tal disparidade trata-se de algo que vem se mostrando intransponível, sendo assim, o presente artigo não se propõe a discutir questões normativas no que diz respeito ao funcionamento ideal da democracia e do sistema de financiamento de campanha. O que se busca aqui é analisar, com base em dados empíricos, como se deu a distribuição dos recursos financeiros entre mulheres e homens em diferentes estados, nas competições proporcionais das eleições de 2014. E se essa plausível diferença afetou o desempenho eleitoral dos competidores.

\section{Sobre dinheiro e votos}

O levantamento bibliográfico destaca dois pontos cruciais em relação ao peso do dinheiro nas eleições. O primeiro é que, atualmente, prevalece nas pesquisas acadêmicas um consenso de que nos pleitos eleitorais faz-se necessário um montante cada vez maior de dinheiro para se eleger. Apesar disso, e aqui apresenta-se o segundo ponto, não é possível pensar que a relação entre dinheiro e voto é simples, direta e explicativa em si mesma. Pelo contrário, estamos tratando de uma relação complexa, na qual outros fatores atuam e interferem. (CERVI, 2013; NASSMACHER, 2003; ZOVATTO, 2005)

Sendo assim, salienta-se que mesmo com a utilização das variáveis financiamento de campanha e gênero para a análise do desempenho eleitoral dos/as concorrentes, com o intuito de observar a distribuição dos recursos financeiros e a desenvoltura eleitoral de homens e mulheres nos diferentes estados, não se ignora que são muitos os fatores que influenciam no processo de participação na competição política, principalmente no caso das mulheres. Todavia, acredita-se que a averiguação da persistência (ou não) do subfinanciamento feminino, juntamente com o ainda baixo número de candidatas eleitas, são por si só achados pertinentes, independentemente das demais variáveis envolvidas. 


\section{Análise das eleições para a Câmara dos Deputados em 2014}

Nas eleições de 2014, o eleitorado brasileiro escolheu seus representantes para os seguintes cargos: Presidente da República, governadores de Estados e do Distrito Federal, Senadores da República, Deputados Federais, Estaduais e Distritais. Com relação à Câmara dos Deputados, 513 representantes são eleitos em distritos plurinominais ${ }^{6}$.

Em 2014, observou-se um total de 2240 (31,66\%) mulheres e 4835 (68,34\%) homens candidatos para o cargo de deputado federal, totalizando 7075 candidaturas, porém somente 5845 foram deferidas. Destas 1711 foram candidaturas femininas (29,27\%) e 4134 (70,73\%) masculinas. Nota-se que no montante geral, o número de mulheres candidatas ultrapassa o percentual mínimo das cotas. Desconsiderando-se os registros indeferidos esse número diminui, o percentual continua, no entanto, muito próximo dos $30 \%$.

Utilizando um desenho quantitativo de pesquisa, com dados coletados do site do Tribunal Superior Eleitoral (TSE), o artigo apresenta dados eleitorais (aptidão para se candidatar, situação eleitoral - eleito/a e não eleito/a, estado (UF) de candidatura, partido político, total de votos e receita total declarada) dos 5845 candidatos a deputado federal, nas eleições de 2014. Os dados foram trabalhados com o procedimento de estatísticas descritivas e dois testes estatísticos, o teste do qui-quadrado ${ }^{7}$ e os resíduos padronizados ${ }^{8}$.

Dois procedimentos utilizados na análise são os cálculos de razão simples e razão de chances. Esta última, também conhecida como razão de probabilidades (odds ratio), é comumente aplicada sobre dois grupos de dados. Essencialmente, ela avalia qual evento é mais provável de ocorrer em um dado grupo (Grupo 1), e a chance de ocorrer em um outro grupo (Grupo 2). Se o resultado for igual a 1, o evento tem a mesma probabilidade de ocorrer em ambos os grupos. Se for maior que 1, é mais provável de ocorrer no Grupo 1. E se for menor que 1, é mais provável de ocorrer no Grupo 2. É válido lembrar que o Grupo 1 é sempre aquele que se busca avaliar.

\footnotetext{
${ }^{6}$ Cada circunscrição eleitoral, que corresponde à divisão geográfica/administrativa das Unidades Federativas, tem peso variado e se dá conforme o tamanho populacional de cada estado. Atualmente, as bancadas são compostas de no mínimo oito parlamentares e, no máximo, 70. Lembrando que assim como para outros cargos do Legislativo, tem-se a adoção do sistema proporcional de lista aberta, no qual os partidos apresentam uma lista de candidaturas, sem ordenamento prévio, ficando a cargo do eleitor votar no nome de sua preferência. Existe também o chamado voto na legenda, neste caso, o eleitor vota apenas na legenda partidária, sem indicar um candidato específico.

7 Este teste indica se existem diferenças entre o valor observado e o valor esperado em uma distribuição de frequência. Neste trabalho, buscou-se rejeitar a hipótese nula de independência entre a variável gênero e a variável aptidão para se candidatar.

${ }^{8} \mathrm{O}$ teste do qui-quadrado permite a verificação dos valores que sobram (para mais ou para menos) quando a distribuição entre o valor observado e o esperado não é aleatória (CERVI, 2014b). Os resíduos padronizados são essas diferenças. Buscou-se observar se houve, ou não, concentração ou ausência de homens e mulheres no grupo de pessoas aptas e no grupo de pessoas não aptas.
} 
(BLAND; ALTMAN, 2000). No caso deste trabalho, o Grupo 1 corresponde às mulheres e o Grupo 2 aos homens.

Os dados foram trabalhados em três programas. O primeiro, Microsoft Excel, armazenou os bancos de dados das eleições e possibilitou a elaboração de algumas tabelas descritivas e de alguns gráficos. Além dele, o programa Numbers também foi utilizado para a feitura de tabelas e gráficos. Por fim, com o programa estatístico R foram elaborados os gráficos boxplot.

Ressalta-se que este estudo é de natureza quantitativa e, sendo assim, sofre das limitações inerentes a esse tipo de abordagem. Como já mencionado, não se ignora que outros fatores são importantes tanto para a candidatura, quanto para o desempenho eleitoral, como, por exemplo, os capitais políticos e sociais dos/as concorrentes. Tais fatores estão positivamente correlacionados ao financiamento de campanha, ou seja, candidatos com mais acesso a esses recursos, terão maior facilidade para arrecadar fundos de campanha. Lembrando que, na maioria dos casos, as mulheres carecem tanto de capitais político e social, quanto de recursos financeiros pessoais, o que faz com que elas entrem na competição política em desigualdade de condições com os homens (SACCHET; SPECK, 2012b). A análise aqui proposta não aprofunda nos dados que pudessem apontar esses capitais, em virtude da escassez ou da simples inexistência de informações sobre todos/as os/as concorrentes. Ainda assim, neste trabalho, abordam-se problemas de pesquisa inspirados em outras análises com objetivos semelhantes, visando contribuir para o avanço dos estudos de gênero na política, mais especificamente, das mulheres no financiamento de campanhas.

\section{Candidaturas femininas em 2014: panorama geral}

Nas eleições de 2014, notou-se um aumento considerável no número de candidatas para quase todos os cargos. No geral, houve um crescimento de 46,5\% na quantidade de mulheres disputando o pleito em comparação a 2010. Foram 8131 candidaturas femininas, $31,7 \%$ do total de candidaturas que foi de 26172. Quando consideramos o percentual de candidaturas aptas, o número total cai para 22530 registros, sendo 6449 registros femininos. Sendo assim, o percentual de mulheres na disputa cai para 28,62\%. A análise de Junckes et. al. (2015), das eleições de 2010, mostrou que apenas $20 \%$ do total de candidaturas femininas foram consideradas aptas. Ou seja, apesar do não cumprimento das cotas, vê-se um aumento significativo no percentual de mulheres aptas concorrendo ao pleito. 
Foi na disputa para os cargos proporcionais que se observou um maior aumento no número de registros femininos. As disputas estaduais/distrital contaram com 6413 mulheres candidatas, contra 3572 em 2010. Para a Câmara dos Deputados, como já mencionado, foram 1711 (29,3\%) de candidaturas femininas, um aumento de $45 \%$ em comparação a 2010, quando houve 930 candidatas aptas para o pleito.

A tabela 1 expõe o número total de candidaturas e de candidaturas aptas, segundo o gênero, nas eleições de 2014, para o cargo de deputado federal.

\section{TABELA 1 - CANDIDATURAS E CANDIDATURAS APTAS PARA A CÂMARA DOS DEPUTADOS, SEGUNDO GÊNERO 2014}

\begin{tabular}{ccccc}
\hline GÊNERO & CANDIDATURAS & $\%$ & $\begin{array}{c}\text { CANDIDATURAS } \\
\text { APTAS }\end{array}$ & $\%$ \\
\hline HOMENS & 4835 & 68,34 & 4134 & 70,73 \\
MULHERES & 2240 & 31,66 & 1711 & 29,27 \\
TOTAL & $\mathbf{7 0 7 5}$ & $\mathbf{1 0 0}$ & $\mathbf{5 8 4 5}$ & $\mathbf{1 0 0}$ \\
\hline
\end{tabular}

FONTE: elaboração própria com dados do TSE (2015)

Apesar desse aumento no número de mulheres aptas ao pleito no ano de 2014, elas ainda possuem uma elevada presença no grupo dos inaptos, quando comparadas aos homens. Das 1230 candidaturas inaptas, 529 foram mulheres e isso é equivalente a 23,62\% de todas as candidaturas femininas apresentadas. Já para os homens, o percentual de inaptos representou somente 16,96\% do total de concorrentes. Com o teste do qui-quadrado, pode-se rejeitar a hipótese nula de que não existem diferenças significativas entre as distribuições comparadas, ou seja, ser homem ou ser mulher (gênero), e estar apto/a ou não (aptidão eleitoral). A estatística do teste foi de 87,97, valor muito acima do limite crítico, que no caso seria de 3,84 para um nível de confiança de $95 \%$. Rejeitada a hipótese nula, a análise dos resíduos padronizados mostra as concentrações de valores. (Tabela 2)

\section{TABELA 2 - RESÍDUOS PADRONIZADOS PARA CANDIDATURAS APTAS E NÃO APTAS PARA A CÂMARA DOS DEPUTADOS, POR GÊNERO 2014}

\begin{tabular}{ccc}
\hline \multicolumn{3}{c}{ RESİDUO PADRONIZADO } \\
\hline & MULHERES & HOMENS \\
Aptas/os & $-3,374$ & 2,170 \\
$\begin{array}{c}\text { Não } \\
\text { aptas/os }\end{array}$ & 6,068 & $-5,271$ \\
\hline FONTE: elaboração própria com dados do TSE (2015)
\end{tabular}


Com os resíduos padronizados pode-se identificar de forma individual a concentração de valores em pares de casos - acima ou abaixo - do esperado. Estabelecendo-se um nível de confiança de $95 \%$, tem-se como ponto de corte para a significância estatística de falta ou excesso de ocorrência entre as variáveis o valor de +/- 1,96. Sendo assim, nota-se, em relação às mulheres, uma ausência destas no grupo de candidaturas aptas (sinal negativo) e uma concentração maior que a esperada no grupo de candidaturas não aptas (sinal positivo). Já para os homens, estes estão ausentes do grupo de candidaturas não aptas e possuem mais concentração no grupo das candidaturas aptas. Assim sendo, ambas as análises decorrentes do teste do qui-quadrado revelam que, primeiramente, o gênero faz diferença quando se pensa em aptidão ou não para o pleito e, além disso, mostra que apesar do aumento no número de candidaturas femininas, existe uma grande ocorrência de casos de inaptidão de mulheres, maior do que de seus pares masculinos.

Após a exposição dos números de candidaturas, passa-se para a situação eleitoral dos concorrentes, a fim de observar como foi o desempenho eleitoral das candidatas. (Tabela 3 )

TABELA 3 - CANDIDATURAS ELEITAS E NÃO ELEITAS PARA A CÂMARA DOS DEPUTADOS, SEGUNDO GÊNERO 2014

\begin{tabular}{cccccc}
\hline $\begin{array}{l}\text { SITUAÇÃO } \\
\text { ELEITORAL }\end{array}$ & CANDIDATOS & \multicolumn{2}{c}{ MULHERES } & \multicolumn{2}{c}{ HOMENS } \\
\hline Eleito & 513 & 51 & $3,0 \%$ & 462 & $11,2 \%$ \\
Não eleito & 5332 & 1660 & $97,0 \%$ & 3672 & $88,8 \%$ \\
TOTAL & $\mathbf{5 8 4 5}$ & $\mathbf{1 7 1 1}$ & $\mathbf{1 0 0 \%}$ & $\mathbf{4 1 3 4}$ & $\mathbf{1 0 0 \%}$ \\
\hline
\end{tabular}

FONTE: elaboração própria com dados do TSE (2015)

A tabela acima mostra que do total de mulheres que se candidatou para o cargo de deputado federal, apenas $3 \%$ foi eleito. No caso dos homens, do total de concorrentes, $11,2 \%$ se elegeram.

\section{Mulheres e receitas: análise da distribuição dos recursos de campanha}

Passa-se agora para análise dos montantes declarados nas receitas de campanha do pleito de 2014. A Tabela 4 apresenta as médias das receitas de todos dos candidatos concorrentes. 
TABELA 4 - RECEITA TOTAL DOS CANDIDATOS E ELEITOS, POR GÊNERO, PARA A CÂMARA DOS DEPUTADOS 2014

\begin{tabular}{ccll}
\hline $\begin{array}{c}\text { SITUAÇÃO } \\
\text { ELEITORAL }\end{array}$ & $\begin{array}{c}\text { NÚMERO DE } \\
\text { CANDIDATOS }\end{array}$ & RECEITA TOTAL & $\begin{array}{c}\text { RECEITA } \\
\text { MÉDIA }\end{array}$ \\
\hline $\begin{array}{c}\text { Eleitos/as } \\
\text { Não } \\
\text { eleitos/as }\end{array}$ & 513 & $\mathrm{R} \$ 737.359 .553,00$ & $\mathrm{R} \$ 1.437 .348,06$ \\
$\begin{array}{c}\text { Eleitas } \\
\text { Não eleitas }\end{array}$ & 5141 & $\mathrm{R} \$ 423.698 .278,00$ & $\mathrm{R} \$ 95.406,05$ \\
Eleitos & 462 & $\mathrm{R} \$ 65.930 .204,00$ & $\mathrm{R} \$ 1.292 .749,10$ \\
Não eleitos & 3119 & $\mathrm{R} \$ 47.810 .417,00$ & $\mathrm{R} \$ 36.165,22$ \\
\hline \multicolumn{2}{c}{ FONTE: elaboração própria com dados do TSE (2015) }
\end{tabular}

Para a elaboração da tabela acima, foram considerados todos os casos de candidaturas deferidas. Sendo assim, não foram ignorados os casos com receita declarada igual a zero. Optou-se por isso com a intenção de apresentar um quadro mais próximo possível da realidade. É válido lembrar que nas eleições de 2014 o financiamento por pessoas jurídicas ainda era permitido.

Comparando primeiramente a receita média de eleitos e não eleitos, nota-se que os primeiros gastam, em média, 18 vezes mais que os segundos. Comparando a receita média de mulheres eleitas e não eleitas, tem-se que estas gastam pouco mais de $2 \%$ da média gasta pelas eleitas. Quando se analisa os dados masculinos, encontra-se que o grupo dos não eleitos gasta $7 \%$ da receita média dos eleitos. Nota-se que a diferença de receita entre eleitos e não eleitos é grande para homens e mulheres. Porém, estas apresentam uma diferença maior entre os grupos. Observando a receita média de homens e mulheres eleitas, percebe-se que existe uma diferença entre os grupos, pois a receita das mulheres eleitas totaliza, aproximadamente, $89 \%$ da receita masculina. Porém, quando se analisa a receita média de homens e mulheres não eleitos, vê-se que a receita feminina é de, aproximadamente, $28 \%$ da receita masculina. É interessante notar também que as médias de receitas das mulheres, eleitas e não eleitas, estão abaixo da média total. Já as receitas médias dos grupos masculinos, sejam eleitos ou não, ficaram acima da média total. 
GRÁFICO 1 - RECEITA DECLARADA POR GÊNERO, 2014

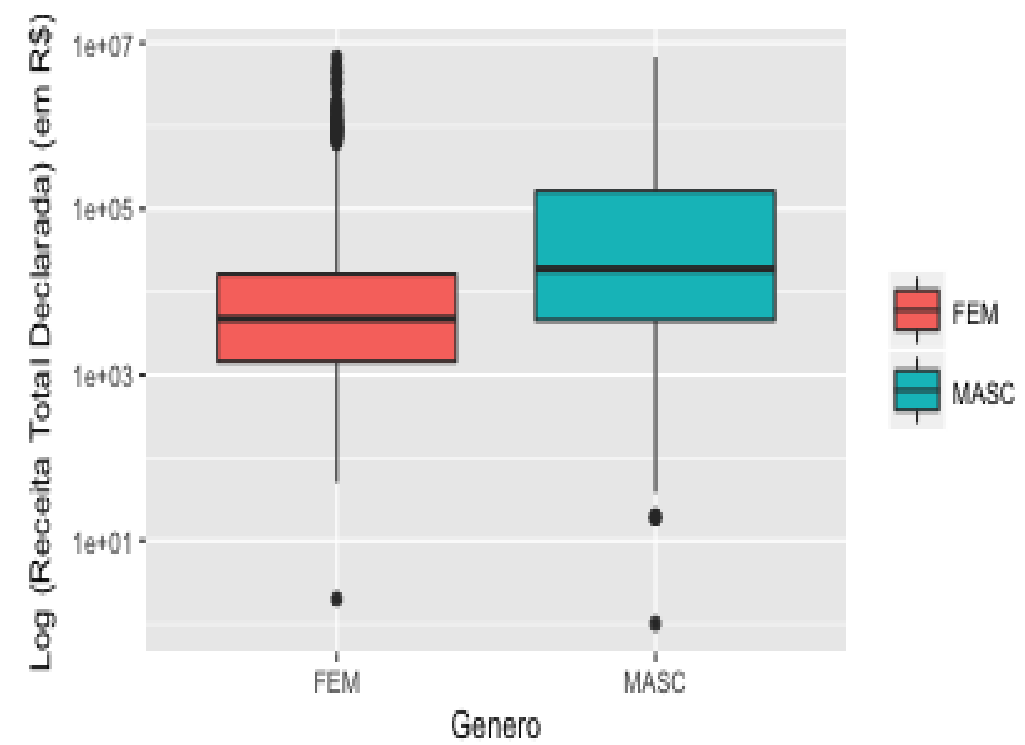

FONTE: elaboração própria com dados do TSE (2015)

GRÁFICO 2 - RECEITA DECLARADA POR GÊNERO E SITUAÇÃO ELEITORAL, 2014

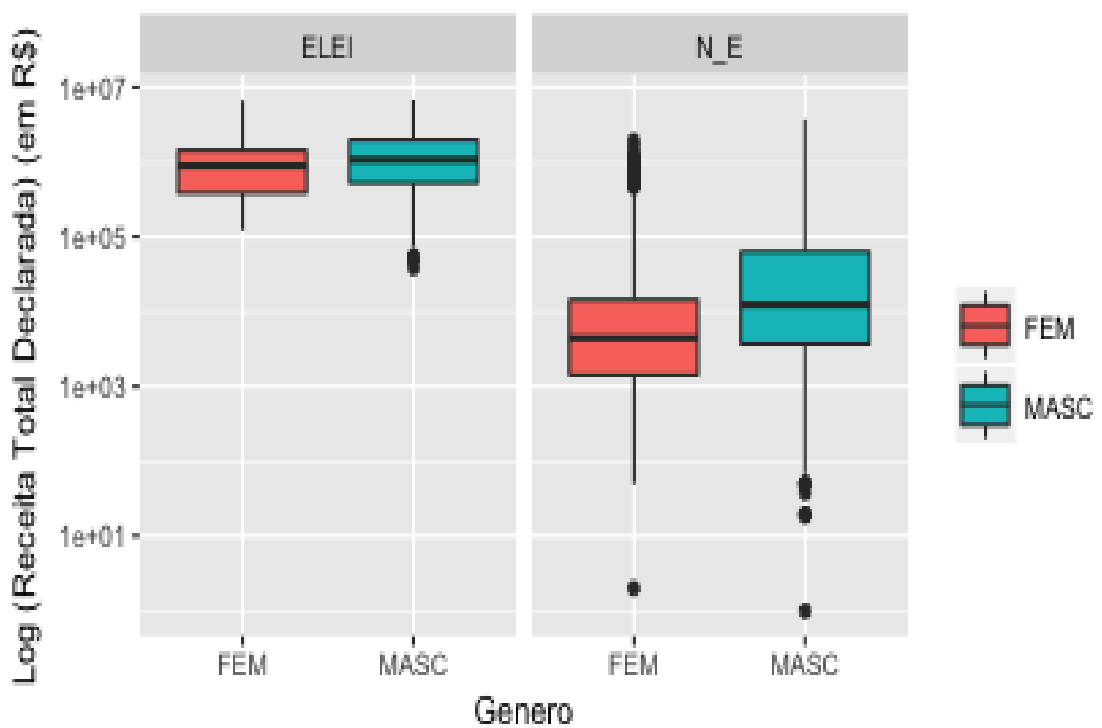

FONTE: elaboração própria com dados do TSE (2015) 
O gráfico $2^{9}$ mostra que os homens possuem receita declarada superior à das mulheres. Mesmo comportamento verificado no gráfico 7, independentemente da situação eleitoral. Somente no grupo dos eleitos/as, verifica-se que a diferença entre as médias e medianas dos candidatos/as é menor do que a média e medianas entre os candidatos não eleitos. Como comentado anteriormente, o gráfico 7 mostra que quando eleitos/as, homens e mulheres tendem a ter menos diferença de receita, visto que todos estão no quartil superior da base de dados (independentemente do gênero). Os valores grafados nos boxplots estão também expostos na Tabela 5.

TABELA 5 - VALORES DAS RECEITAS DECLARADAS, POR GÊNERO, 2014 (R\$)

\begin{tabular}{lcccc}
\hline & $\begin{array}{c}\text { MULHERES } \\
\text { ELEITAS }\end{array}$ & $\begin{array}{c}\text { HOMENS } \\
\text { ELEITOS }\end{array}$ & $\begin{array}{c}\text { MULHERES } \\
\text { NÃO } \\
\text { ELEITAS }\end{array}$ & $\begin{array}{c}\text { HOMENS } \\
\text { NÃO } \\
\text { ELEITOS }\end{array}$ \\
\hline $\mathrm{N}$ & 51 & 462 & 1.660 & 3.672 \\
Mediana & 892.647 & 1.078 .294 & 2.426 & 7.834 \\
Maior & 6.723 .540 & 6.832 .481 & 1.925 .588 & 3.672 .565 \\
Desvio & 1.401 .533 & 1.250 .802 & 120.850 & 305.663 \\
Média & 1.292 .749 & 1.453 .310 & 28.801 & 102.366 \\
Tipo de & Direita & Direita & Direita & Direita \\
Assimetria & & & & \\
\hline
\end{tabular}

FONTE: elaboração própria com dados do TSE (2015)

Comparando os dados das eleições de 2014 com os das eleições de 2010 (Tabela 6), levantam-se alguns pontos. Em primeiro lugar, nota-se que houve um esperado aumento no montante declarado de receita de um pleito para o outro, de aproximadamente $29 \%{ }^{10}$. Analisando os grupos de eleitos e não eleitos, percebe-se que no primeiro, tanto homens quanto mulheres tiveram uma elevação no valor da receita média, sendo de $29 \%$ para eles e de $28,5 \%$ para elas. Lembra-se que houve um aumento de $13,3 \%$ de candidatas eleitas, e um decréscimo de aproximadamente $1 \%$ de candidatos eleitos. Já no grupo dos não eleitos, ao contrário de seus pares masculinos que tiveram um aumento de 18,5\% na receita média, as mulheres tiveram um decréscimo de $15 \%$ na mesma. Os dados evidenciam que a diferença entre o financiamento de homens e de mulheres vem sendo expressiva e crescente.

\footnotetext{
${ }^{9}$ Os gráficos 3 e 4 foram realizados com os valores das receitas declaradas convertidos aos seus logarítimos naturais, para que as distribuições se aproximassem de uma normal, para efeito ilustrativo.

${ }^{10}$ Vale lembrar que o montante total não foi deflacionado e que a inflação medida pelo IGP-M/FGV no período out/2010-out/2011 foi de 25,88\%, de modo que o aumento real não foi tão expressivo entre os dois pleitos.
} 
TABELA 6 - RECEITA TOTAL DOS CANDIDATOS E ELEITOS, POR GÊNERO, PARA A CÂMARA DOS DEPUTADOS 2010

\begin{tabular}{cccc}
\hline $\begin{array}{c}\text { SITUAÇÃO } \\
\text { ELEITORAL }\end{array}$ & $\begin{array}{c}\text { NÚMERO DE } \\
\text { CANDIDATOS }\end{array}$ & $\begin{array}{c}\text { RECEITA } \\
\text { TOTAL }\end{array}$ & $\begin{array}{c}\text { RECEITA } \\
\text { MÉDIA }\end{array}$ \\
\hline $\begin{array}{c}\text { Eleitos/as } \\
\text { Não } \\
\text { eleitos/as }\end{array}$ & 513 & $\mathrm{R} \$ 569.923 .457,00$ & $\mathrm{R} \$ 1.110 .961,90$ \\
Eleitas & 4369 & $\mathrm{R} \$ 330.920 .833,00$ & $\mathrm{R} \$ 75.742,92$ \\
Não eleitas & 885 & $\mathrm{R} \$ 45.273 .982,00$ & $\mathrm{R} \$ 1.006 .088,49$ \\
Eleitos & 468 & $\mathrm{R} \$ 29.945 .021,00$ & $\mathrm{R} \$ 33.836,18$ \\
Não eleitos & 3484 & $\mathrm{R} \$ 300.975 .812,00$ & $\mathrm{R} \$ 86.388,01$ \\
\hline
\end{tabular}

FONTE: elaboração própria com dados do TSE (2015)

\section{Estados e Regĩ̃es}

A análise das candidaturas por região mostra que, nas eleições de 2014, somente duas, das cinco regiões brasileiras, cumpriram o percentual obrigatório das cotas. São elas: a região Norte $(32,95 \%)$ e a Centro-Oeste $(31,33 \%)$. As mesmas regiões apresentam um percentual de eleitas mais elevado, com destaque para a região Norte, onde 23,07\% dos assentos foram ocupados por mulheres. O Centro-Oeste, apesar de estar no segundo lugar, apresentou um percentual de apenas $9,75 \%$, que está pouco distante das demais regiões. O pior desempenho feminino ficou na região Nordeste, com apenas 6,21\% das vagas preenchidas por candidatas. O Sul, segundo pior colocado, apresentou um percentual muito semelhante de 6,5\%. (Tabela 7)

TABELA 7 - CANDIDATURAS E DEPUTADOS FEDERAIS ELEITOS PARA A CÂMARA DOS DEPUTADOS, POR GÊNERO, SEGUNDO REGIÕES 2014

\begin{tabular}{ccccccccc}
\hline REGIÃO & MULHERES & $\%$ & ELEITAS & $\%$ & HOMENS & $\%$ & ELEITOS & $\%$ \\
\hline Norte & 202 & 32,95 & 15 & 23,07 & 411 & 67,05 & 50 & 76,93 \\
Nordeste & 359 & 28,27 & 10 & 6,21 & 911 & 71,73 & 141 & 93,79 \\
$\begin{array}{c}\text { Centro- } \\
\text { Oeste }\end{array}$ & 130 & 31,33 & 4 & 9,75 & 285 & 68,67 & 37 & 90,25 \\
$\begin{array}{c}\text { Sudeste } \\
\text { Sul }\end{array}$ & 808 & 28,51 & 17 & 9,50 & 2026 & 71,49 & 162 & 90,50 \\
Total & $\mathbf{1 7 1 1}$ & $\mathbf{2 9 , 7 3}$ & $\mathbf{5}$ & $\mathbf{6 , 5}$ & 501 & $\mathbf{7 0 , 2 7}$ & $\mathbf{7 2}$ & $\mathbf{9 3 , 5 0}$ \\
\hline
\end{tabular}

FONTE: elaboração própria com dados do TSE (2015)

Utilizando os dados das eleições de 2010 (Tabela 8), observa-se que, no pleito de 2014, houve um aumento no número de candidaturas femininas em todas as regiões, ressaltando que na competição passada nenhuma delas atingiu o percentual mínimo de 30\%. Passando para o percentual de eleitas, vê-se que o número de mulheres nesse grupo pouco sofreu alteração. Também em 2010, a região Norte foi a que apresentou um percentual maior de mulheres concorrentes e de 
mulheres eleitas $-23,00 \%$ e $15,38 \%$, respectivamente. O Sul é o que teve o pior resultado, com apenas $6,49 \%$ de seus assentos ocupados por mulheres, praticamente o mesmo percentual das eleições de 2014. É interessante ressaltar que apesar de duas regiões atingirem a cota e as demais ficarem muito próximas disso, houve uma ínfima alteração no número de eleitas. No Nordeste, por exemplo, observou-se um aumento significativo de mulheres concorrentes, de 14,81\% para 28,27\%, mas houve uma piora do desempenho eleitoral feminino, pois de 7,28\%, em 2010, passou-se para $6,21 \%$, em 2014.

TABELA 8 - CANDIDATURAS E DEPUTADOS FEDERAIS ELEITOS PARA A CÂMARA DOS DEPUTADOS, POR GÊNERO, SEGUNDO REGIÕES 2010

\begin{tabular}{ccccccccc}
\hline REGI $\tilde{A} O$ & MULHERES & $\%$ & ELEITAS & $\%$ & HOMENS & $\%$ & ELEITOS & $\%$ \\
\hline Norte & 101 & 23,00 & 10 & 15,38 & 338 & 77,00 & 55 & 84,62 \\
Nordeste & 154 & 14,81 & 11 & 7,28 & 886 & 85,19 & 140 & 92,72 \\
$\begin{array}{c}\text { Centro- } \\
\text { Oeste }\end{array}$ & 70 & 20,23 & 4 & 9,76 & 276 & 79,77 & 37 & 90,24 \\
Sudeste & 455 & 19,14 & 15 & 8,37 & 1921 & 80,86 & 164 & 91,63 \\
$\quad$ Sul & 150 & 22,06 & 5 & 6,49 & 530 & 77,94 & 72 & 93,51 \\
Total & $\mathbf{9 3 0}$ & $\mathbf{9 9 , 2 4}$ & $\mathbf{4 5}$ & $\mathbf{8 , 7 8}$ & $\mathbf{3 9 5 1}$ & $\mathbf{4 0 0 , 7 6}$ & $\mathbf{4 6 8}$ & $\mathbf{9 1 , 2 2}$ \\
\hline
\end{tabular}

FONTE: elaboração própria com dados do TSE (2015)

A constatação de melhor desempenho feminino na região Norte e de pior desempenho na região Sul, corrobora com os achados de Araújo e Alves (2007) que afirmam haver maiores chances das mulheres serem eleitas em estados e regiões com menores IDHs ${ }^{11}$. Já a análise feita por estado aponta que houve um melhor desempenho eleitoral feminino naqueles com índices considerados altos e médios (Amapá, 0,708, Tocantins 0,699, Rondônia 0,690, Roraima 0,707 e Piauí 0,646 ${ }^{12}$ ). Essa variação que ocorre entre os estados brasileiros, seja em relação ao número de candidaturas lançadas ou ao percentual de mulheres eleitas, mostra que os aspectos relacionados à engenharia do sistema político são insuficientes para a explicação da dificuldade de acesso das mulheres à representação política. Pois enquanto a representação de alguns estados é composta quase que $40 \%$ por mulheres, alguns não elegeram sequer uma deputada federal.

\footnotetext{
11 Segundo Araújo e Alves (2007), o Índice de Desenvolvimento Humano (IDH) tem servido como principal indicador de desenvolvimento em estudos comparados, inclusive os estudos de gênero, servindo também para comparações internas às regiões e Estados em cada país. Na divulgação do IDH, feita pelo Pnud, em 2010, a média dos Estados da região Norte foi de 0,693 e da região Sul de 0,756. Lembrando que quanto mais próximo de 1, maior o desenvolvimento humano. (ARAÚJO \& ALVES, 2007, p. 539)

${ }^{12}$ A classificação dos valores do IDH são: 0,800 - 1 (Muito alto), 0,700 - 0,799 (Alto), 0,600 - 0,699 (Médio), 0,500 0,599 (Baixo), 0 - 0,499 (Muito baixo). (PNUD, BRASIL, 2010)
} 
Continuando a análise dos estados, nota-se que em 11 deles não foram cumpridas as cotas partidárias: Alagoas (28,57\%), Bahia (26,13\%), Goiás (27,17\%), Maranhão (25,57\%), Mato Grosso (29,06\%), Pernambuco (26,31\%), Paraíba (28,40\%), Paraná (27,87\%), Rio de Janeiro (26,91\%) e São Paulo $(28,18 \%)$. Os demais estados apresentaram $30 \%$ ou mais de candidatas.

Em relação aos eleitos, os estados com o melhor desempenho feminino foram o Tocantins e o Amapá, onde 37,5\% dos assentos foram ocupados por mulheres. Na sequência, tem-se os estados de Rondônia e Roraima, ambos com 25\% de eleitas. Outro estado com um percentual mais elevado foi o Piauí, com 20\%. Das cinco Unidades Federativas citadas, quatro são da região Norte e os quatros possuem uma menor magnitude eleitoral, apenas 8 cadeiras em disputa, o que corrobora com a afirmação de Araújo e Borges (2007) de que as mulheres apresentam maiores chances de serem eleitas nas menores UFs. É interessante notar que no Tocantins tem-se o menor número de mulheres candidatas (15), bem como o menor número de competidores (46). Em cinco estados não houve nenhuma mulher eleita, sendo eles: Alagoas, Espírito Santo, Mato Grosso, Paraíba e Sergipe, todos com um percentual próximo ou maior que $30 \%$ de candidaturas femininas. $(28,57 \%$, 30,34\%, $29,06 \%, 28,40 \%$ e $34,72 \%$, respectivamente)

Analisando a razão entre a receita média de homens e mulheres, nota-se que em apenas seis estados (Acre, Amapá, Mato Grosso do Sul, Piauí, Rio Grande do Norte e Rondônia) a receita feminina ficou acima de $50 \%$ da receita masculina. Desses estados, três apresentaram maior número de mulheres eleitas, Amapá, única localidade onde a receita média feminina ultrapassou a masculina, Rondônia e Piauí. Nos estados da Paraíba e do Mato Grosso, a receita média das mulheres foi menor que $10 \%$ de seus pares masculinos. Lembra-se que ambas as Unidades Federativas não elegeram nenhuma mulher.

Dando continuidade no desempenho feminino por estado, a análise da razão de chances de eleição nos mostra que os únicos Estados onde as mulheres tiveram melhor desempenho eleitoral que os homens foram o Amapá $(1,22)$ e o Tocantins $(1,3)$. Nos demais, a probabilidade de eleição ficou concentrada no grupo dos homens. (Tabela 9)

É válido colocar que a "Razão das médias das receitas" foi calculada por meio da divisão da receita média das mulheres, pela receita média dos homens ${ }^{13}$. Já a "Razão de chances", ou razão de probabilidade, foi calculada com a utilização da divisão de eleitos/as por candidatos/as, para mulheres e homens ${ }^{14}$.

\footnotetext{
${ }^{13}$ Fórmula da razão de médias: $\bar{X}=\frac{1}{n} \sum_{i=1}^{n} X_{i}$

${ }^{14} R=\frac{p(1-q)}{q(1-p)}$
} 
TABELA 9 - RELAÇÃO ENTRE FINANCIAMENTO E ELEIÇÃO DE MULHERES PARA O CARGO DE DEPUTADO FEDERAL, SEGUNDO ESTADOS 2014

\begin{tabular}{|c|c|c|c|c|c|c|c|c|c|c|c|}
\hline \multirow[t]{2}{*}{ UF } & \multicolumn{3}{|c|}{ Candidatos } & \multicolumn{3}{|c|}{ Eleitos } & \multicolumn{3}{|c|}{ Receita (em Reais) } & \multirow{3}{*}{$\begin{array}{c}\text { Razão de } \\
\text { chances de } \\
\text { eleição } \\
(\mathrm{M} / \mathrm{H}) \\
0,24\end{array}$} & \multirow{2}{*}{$\begin{array}{c}\text { Razão das } \\
\text { médias das } \\
\text { receita } \\
(\mathrm{M} / \mathrm{H})\end{array}$} \\
\hline & Mulheres & $\%$ & $\begin{array}{c}\text { Total de } \\
\text { candidatos }\end{array}$ & Mulheres & $\%$ & $\mathrm{~N}$ total & Mulheres & $\begin{array}{l}\% \text { da receita } \\
\text { das mulheres }\end{array}$ & Total da receita & & \\
\hline AC & 21 & 34 & 62 & 1 & $12,5 \%$ & 8 & $\mathrm{R} \$ 25.976,00$ & 30,88 & $\mathrm{R} \$ 8.413 .323,00$ & & 0,87 \\
\hline $\mathbf{A L}$ & 28 & 29 & 98 & 0 & $0,0 \%$ & 9 & $\mathrm{R} \$ 905.563,00$ & 5,21 & $\mathrm{R} \$ 17.395 .967,00$ & 0 & 0,13 \\
\hline $\mathbf{A M}$ & 26 & 34 & 76 & 1 & $12,5 \%$ & 8 & $\mathrm{R} \$ 1.585 .466,00$ & 6,91 & $\mathrm{R} \$ 22.942 .100,00$ & 0,24 & 0,14 \\
\hline $\mathbf{A P}$ & 34 & 33 & 102 & 3 & $37,5 \%$ & 8 & $\mathrm{R} \$ 3.317 .019,00$ & 38,27 & $\mathrm{R} \$ 8.666 .874,00$ & 1,22 & 1,24 \\
\hline BA & 75 & 26 & 287 & 3 & $7,7 \%$ & 39 & $\mathrm{R} \$ 2.650 .387,00$ & 3,70 & $\mathrm{R} \$ 71.720 .814,00$ & 0,20 & 0,10 \\
\hline CE & 58 & 31 & 189 & 2 & $9,1 \%$ & 22 & $\mathrm{R} \$ 2.490 .257,00$ & 7,14 & $\mathrm{R} \$ 34.854 .101,00$ & 0,19 & 0,17 \\
\hline DF & 40 & 32 & 125 & 1 & $12,5 \%$ & 8 & $\mathrm{R} \$ 3.147 .553,00$ & 16,40 & $\mathrm{R} \$ 19.198 .247,00$ & 0,28 & 0,42 \\
\hline ES & 44 & 30 & 145 & 0 & $0,0 \%$ & 10 & $\mathrm{R} \$ 1.758 .377,00$ & 9,52 & $\mathrm{R} \$ 18.464 .833,00$ & 0 & 0,24 \\
\hline GO & 25 & 27 & 92 & 2 & $11,8 \%$ & 17 & $\mathrm{R} \$ 6.910 .039,00$ & 11,29 & $\mathrm{R} \$ 61.206 .514,00$ & 0,30 & 0,34 \\
\hline MA & 56 & 26 & 219 & 1 & $5,6 \%$ & 18 & $\mathrm{R} \$ 1.458 .643,00$ & 6,94 & $\mathrm{R} \$ 21.022 .647,00$ & 0,15 & 0,22 \\
\hline MG & 185 & 31 & 596 & 5 & $9,4 \%$ & 53 & $\mathrm{R} \$ 13.849 .472,00$ & 8,78 & $\mathrm{R} \$ 157.664 .755,00$ & 0,21 & 0,21 \\
\hline MS & 40 & 36 & 112 & 1 & $12,5 \%$ & 8 & $\mathrm{R} \$ 6.325 .045,00$ & 21,82 & $\mathrm{R} \$ 28.990 .815,00$ & 0,24 & 0,50 \\
\hline MT & 25 & 29 & 86 & 0 & $0,0 \%$ & 8 & $\mathrm{R} \$ 665.736,00$ & 2,62 & $\mathrm{R} \$ 2.539 .012,00$ & 0 & 0,06 \\
\hline PA & 54 & 32 & 170 & 3 & $17,6 \%$ & 17 & $\mathrm{R} \$ 3.446 .118,00$ & 17,92 & $\mathrm{R} \$ 19.235 .559,00$ & 0,43 & 0,47 \\
\hline PB & 25 & 28 & 88 & 0 & $0,0 \%$ & 12 & $\mathrm{R} \$ 92.000,00$ & 0,68 & $\mathrm{R} \$ 13.575 .527,00$ & 0 & 0,02 \\
\hline PE & 40 & 26 & 152 & 1 & $4,0 \%$ & 25 & $\mathrm{R} \$ 2.792 .594,00$ & 5,50 & $\mathrm{R} \$ 50.779 .732,00$ & 0,09 & 0,16 \\
\hline PI & 28 & 33 & 85 & 2 & $20,0 \%$ & 10 & $\mathrm{R} \$ 8.007 .439,00$ & 32,77 & $\mathrm{R} \$ 24.431 .866,00$ & 0,47 & 0,99 \\
\hline PR & 80 & 28 & 287 & 2 & $6,7 \%$ & 30 & $\mathrm{R} \$ 2.656 .615,00$ & 3,85 & $\mathrm{R} \$ 69.080 .298,00$ & 0,16 & 0,10 \\
\hline $\mathbf{R J}$ & 232 & 27 & 862 & 6 & $13,0 \%$ & 46 & $\mathrm{R} \$ 13.558 .562,00$ & 12,56 & $\mathrm{R} \$ 107.987 .735,00$ & 0,39 & 0,39 \\
\hline $\mathbf{R N}$ & 24 & 30 & 80 & 1 & $12,5 \%$ & 8 & $\mathrm{R} \$ 2.655 .759,00$ & 18,78 & $\mathrm{R} \$ 14.144 .958,00$ & 0,30 & 0,54 \\
\hline RO & 25 & 31 & 80 & 2 & $25,0 \%$ & 8 & $\mathrm{R} \$ 4.159 .813,00$ & 24,52 & $\mathrm{R} \$ 16.963 .084,00$ & 0,71 & 0,71 \\
\hline $\mathbf{R R}$ & 27 & 35 & 77 & 2 & $25,0 \%$ & 8 & $\mathrm{R} \$ 1.341 .848,00$ & 17,09 & $\mathrm{R} \$ 7.850 .607,00$ & 0,58 & 0,38 \\
\hline $\mathbf{R S}$ & 95 & 31 & 304 & 1 & $3,2 \%$ & 31 & $\mathrm{R} \$ 3.646 .272,00$ & 6,63 & $\mathrm{R} \$ 55.036 .340,00$ & 0,06 & 0,16 \\
\hline SC & 37 & 30 & 122 & 2 & $12,5 \%$ & 16 & $\mathrm{R} \$ 2.857 .045,00$ & 9,20 & $\mathrm{R} \$ 31.049 .818,00$ & 0,29 & 0,23 \\
\hline SE & 25 & 35 & 72 & 0 & $0,0 \%$ & 8 & $\mathrm{R} \$ 517.145,00$ & 6,79 & $\mathrm{R} \$ 7.617 .477,00$ & 0 & 0,14 \\
\hline SP & 347 & 28 & 1231 & 6 & $8,6 \%$ & 70 & $\mathrm{R} \$ 17.667 .838,00$ & 7,59 & $\mathrm{R} \$ 232.670 .033,00$ & 0,22 & 0,21 \\
\hline TO & 15 & 33 & 46 & 3 & $37,5 \%$ & 8 & $\mathrm{R} \$ 2.680 .402,00$ & 18,23 & $\mathrm{R} \$ 14.703 .655,00$ & 1,3 & 0,46 \\
\hline
\end{tabular}




\section{Principais considerações}

Analisando os valores da receita média de homens e mulheres, observa-se que a diferença de receita entre mulheres eleitas e não eleitas é superior à diferença de seus pares masculinos. Focando nos grupos dos/as eleitos/as, a receita média feminina ficou abaixo da masculina. E mesmo com o aumento no número de candidaturas de mulheres, a receita total delas sofreu uma queda das eleições de 2010 para as eleições de 2014. Em relação à receita e aos partidos políticos, observou-se que a receita das mulheres foi menor do que a dos homens em quase todos os partidos. Nos partidos posicionados mais à esquerda o desempenho eleitoral feminino foi melhor, já nos partidos mais à direita observou-se o contrário.

Em relação às hipóteses levantadas nesta pesquisa, notou-se que existem diferenças significativas na distribuição dos recursos financeiros entre homens e mulheres, ficando estas com um percentual muito menor da receita total na grande maioria dos estados. Sem pretender fazer colocações conclusivas ou mesmo esgotar todas as possibilidades de análise, observou-se que nos partidos onde as receitas das mulheres foram mais próximas às dos homens, o desempenho eleitoral delas foi maior do que o de seus pares masculinos. O que leva a crer que a distribuição das receitas de campanha afetou o desempenho eleitoral das concorrentes.

Colocados esses pontos, pode-se levantar algumas suposições. A primeira é que existe um forte indício de que as cotas partidárias estão sendo cumpridas com a utilização de candidatas "laranjas" que não entram no pleito realmente para competir. O alto número de mulheres inaptas (1/4 das candidaturas femininas) é um dos fatos que possibilita essa conclusão. A segunda é que mesmo que não seja fator único, o financiamento se confirmou como peça-chave para uma real e maior inclusão feminina na política.

Após vinte anos de implementação da política de cotas, percebe-se um lento e pequeno aumento na presença feminina nos cargos político-decisórios. As cotas aparecem como o meio mais imediato na tentativa de alteração no quadro de quase exclusão das mulheres do campo político. Apesar de todo o debate existente entre a representação descritiva, que é o caso da política de cotas, e representação substantiva, pode-se concluir que ao mesmo tempo que a primeira não leva necessariamente à segunda, esta dificilmente aparecerá sem aquela. Ou seja, bem ou mal, as cotas são necessárias como estímulo ao aumento no número de mulheres nos cargos eletivos.

Dada a importância que possui a representação dos mais variados grupos nos espaços decisórios para um bom funcionamento da democracia, a sub-representação feminina aponta uma falha no sistema democrático vigente. Até agora, as cotas têm mostrado resultados, porém, outras 
mudanças são necessárias para que mais mulheres tenham reais oportunidades de se candidatarem, competirem e se elegerem em condições equivalentes às dos homens. Dentre elas podemos citar o fechamento das listas partidárias, por exemplo.

A presente pesquisa analisou os recursos financeiros de campanha a partir de uma perspectiva de gênero. Mostrou que um dos obstáculos centrais para a grande maioria das mulheres que iniciam e participam da vida política é o montante substancial de dinheiro geralmente exigido para a realização de uma campanha e para a vitória nas eleições. Existe uma relação significativa entre ser eleito/a e a quantia de dinheiro arrecadado para a campanha. A falta de recursos afeta homens e mulheres, porém, estas são afetadas de maneira desproporcional, uma vez que que possuem uma situação socioeconômica inferior e consequentemente menor acesso às redes e grupos de financiadores.

Entende-se que os recursos financeiros não explicam por si só a ausência feminina nos espaços de poder, todavia, uma distribuição mais equilibrada entre homens e mulheres possibilitaria uma competição mais justa e consequentemente aprimoraria o processo democrático das eleições.

\section{Referências}

ARAÚJO, C. Participação Política e Gênero: algumas tendências analíticas recentes. BIB, São Paulo, $\mathrm{n}^{\circ}$ 52, 2o semestre, p. 45-77, 2001.

ARAÚJO, C. Partidos Políticos e Gênero: mediações das rotas de ingresso das mulheres na representação política. Rev. Sociol. Polít., Curitiba, 24, p. 193-215, jun. p. 196-197, 2005.

ARAÚJO, C. Cotas Femininas e Financiamento de Campanha. Cadernos Adenauer, São Paulo, v. 1, p. 11-30, 2013.

ARAÚJO, C. e ALVES J. E. D. Impactos de Indicadores Sociais e do Sistema Eleitoral sobre as Chances das Mulheres nas Eleições e suas Interações com as Cotas. Dados - Revista de Ciências Sociais, Rio de Janeiro, vol 50, n.3, p. 535-577, 2007.

ARAÚJO, C., et. al. A construção das democracias ocidentais e o lugar das mulheres in Mulheres e o Poder Legislativo no estado do Rio de Janeiro: lugares, perfis e experiências municipais, CEDIM, Rio de Janeiro, p. 09-14, 2002.

BANCO MUNDIAL. Relatório sobre o desenvolvimento mundial - Igualdade de Gênero e Desenvolvimento. Washington, 2011.

BLAND, J. M.; ALTMAN, D. G. The odds ratio. BMJ, Oxford. May, vol. 320, 2000. 
CAUL, M. Women's Representation in National Legislatures: Explaining Differences Across Advanced Industrial Democracies', paper presented at the WESTERN POLITICAL SCIENCE ASSOCIATION MEETING, 13-15 March, Tucson, Arizona, 1997.

CERVI, E.U. Doações de campanha e desempenho eleitoral: uma análise comparativa sobre as eleições para prefeito de capitais brasileiras em 2008 e 2012. Agenda Política. São Carlos, v. 1, n. 1, p. 26-54, 2013.

CERVI, E.U. Análise de Dados Categóricos em Ciência Política. Programa de Pós-graduação em Comunicação e Pós-graduação em Ciência Política - UFPR, Curitiba, 2014.

DAHL, R. Democracy and Its Critics. New Haven and London: Yale University Press, 1989.

DAHL, R. 2009. Sobre a democracia. Editora UnB, Brasília, 2009.

FIGUEIREDO FILHO, D.B. O elo corporativo? Grupos de interesse, financiamento de campanha e regulação eleitoral. Dissertação de Mestrado. Recife: Universidade Federal de Pernambuco, 2009. Disponível em: http://repositorio.ufpe.br:8080/bitstream/handle/123456789/1301/arquivo1617_1.pdf?sequence=1\& isAllowed=y Data de acesso: 02/05/2016.

GARCÍA, A. Financiamiento político y perspectiva de género. In: GRINER, S.; ZOVATTO, D. (ed.). De las normas a las buenas prácticas: San José: OEA, 2004.

GROSSI, M. P. e MIGUEL, S. M. Transformando a Diferença: as mulheres na política. Estudos Feministas, Florianópolis, p. 167-206, 2001.

HOROCHOVSKI, R. R., et. al. Estruturas de poder nas redes de financiamento político nas eleições de 2010 no Brasil. Opinião Pública, Campinas, vol. 22, nº 1, 2016.

HTUN, M.; JONES, M. P. Engendering the Right to Participate in Decision-Making: Electoral Quotas and Women's Leadership in Latin America. In: CRASKE, N.; MOLYNEUX, M. (eds.). Gender, and the Politics of Rights and Democracy in Latin America. Basingstoke: Palgrave, 2002.

IPU, Inter Parliamentary Union. Disponível em

< http://www.ipu.org/wmn-e/classif.htm>. Data de acesso em 09 out. 2018.

JONES, M. P. Gender Quotas, Electoral Laws, and the Election of Women: Evidence from the Latin American Vanguard. Comparative Political Studies, 42 (1), p.56- 81, 2009.

JUNCKES, I. J. HOROCHOVSKI, R. R., CAMARGO, N. F., SILVA, J. M., SILVA, E. A. e ALMEIRA, L. B. Posicionamento das Mulheres na Rede de Financiamento Eleitoral e seu Desempenho nas Eleições de 2010 no Brasil: a dinâmica estrutural da exclusão e marginalização feminina no poder político. Revista Latino-Americana de Geografia e Gênero - UEPG, Ponta Grossa, v. 6, n. 1, p. 25-47, 2015.

KABEER, Nalia. Resources, Agency, Achievements: Reflections on the Measurement of Women's Empowerment. Development and Change, v. 30, n. 3, p 35-64, 1999. 
LEMOS, L.B.; MARCELINO, D.; PEDERIVA, J.H. Porque dinheiro importa: a dinâmica das contribuições eleitorais para o Congresso Nacional em 2002 e 2006. Opinião Pública, 16(2), p. 366-393, 2010.

LIJPHART, Arend. Patterns of Democracy: Government Forms and Performance in 36 Countries. Yale, New Haven: Yale University Press, 1999.

LOVENDUSKI, J.; NORRIS, P. Gender and Party Politics. Sage, London, 1993.

MANCUSO, W. P. Investimento eleitoral no Brasil: balanço da literatura (2001-2012) e agenda de pesquisa. Rev. Sociol. Polit., v. 23, n. 54, jun., p. 155-183, 2015.

MANCUSO, W. P.; FIGUEIREDO FILHO, D. B. Financiamento empresarial nas campanhas para deputado federal no Brasil (2002-2010): determinantes e consequências. Trabalho apresentado ao $38^{\circ}$ ENCONTRO ANUAL DA ANPOCS. Caxambu, MG, 2014.

MANSBRIDGE, J. Should blacks represent blacks and women represent women? A contingent 'yes'. Journal of Politics, 61(3), p. 628- 657, 1999.

MARCELINO, D. Sobre dinheiro e eleições: um estudo dos gastos de campanha para o

Congresso Nacional em 2002 e 2006. Dissertação de Mestrado. Brasília: Universidade de Brasília, 2010. Disponível em:

http://repositorio.unb.br/bitstream/10482/6669/1/2010_DanielMarcelinodaSilva.pdf Data de acesso: 02/05/2016.

MATLAND, R. Women's representation in national legislatures: developed and deve- loping countries. Legislative Studies Quarterly, 23 (1), p.109- 125, 1998.

MATLAND, R.; BROWN B. D. District Magnitude's Effect on Female Represen- tation in U. S. State Legislatures. Legislative Studies Quarterly. Vol. 17, No. 4 (Nov., 1992), p. 469-492, 1992.

MATLAND, R.; STUDLAR, D.T. The Contagion of Women Candidates in Single- Member District and Proportional Representation Electoral Systems: Canada and Norway. The Journal of Politics, 58, 3, p. 707-33, 1996.

MOSER, R. G. The effects of electoral systems on women's representation in post- -communist states. Electoral Studies, 20 (3), p. 353-369, 2001.

MIGUEL, L. F. Teoria Política Feminista e Liberalismo: o caso das cotas de representação. RBCS, São Paulo, v. 15, n. 44, p. 91-102, 2000.

NASSMACHER, K. H. Introduction: Political Parties, Funding and Democracy. In: AUSTIN, R.; TJERNSTRÖM, M. (orgs.). Handbook on funding of political parties and election Campaigns. Suécia: International IDEA, 2003.

ONU - Organização das Nações Unidas. Transformando o mundo: a Agenda 2030 para o desenvolvimento sustentável. 2015. 
PRZEWORSKI, A. Democracia e mercado no Leste Europeu e na América Latina. Rio de Janeiro: Relume-Dumará, 1994.

REYNOLDS, A. Women in the legislatures and executives of the world: knocking at the highest glass ceiling. World Politics, 51(4), p. 547-572, 1999.

SACCHET, T. Political Parties and Gender in Latin America: an overview of conditions and responsiveness. In: GOETZ, A. M. (org.). Governing Women: Women's Political Effectiveness in Contexts of Democracy and Governance Reform. New York: Routledge, 2008.

SACCHET, T. Democracia pela metade: candidaturas e desempenho eleitoral das mulheres. Cadernos Adenauer, Rio de Janeiro, XIV, n. 2, p. 85-107, 2013.

SACCHET, T.; SPECK, B. W. Financiamento Eleitoral, Representação Política e Gênero: uma análise das eleições de 2006. Opinião Pública, v. 18, p. 177-197. 2012a.

SACCHET, T.; SPECK, B. W Dinheiro e sexo na política brasileira: financiamento de campanha e desempenho eleitoral em cargos legislativos in Mulheres nas eleições 2010. São Paulo: ABCP/Secretaria de Políticas para as Mulheres, 2012b.

SAMUELS, D. Money, Elections, and Democracy in Brazil. Latin American Politics and Society, 43(2), p. 27-48, 2001.

SAMUELS, D. Pork Barreling is not Credit Claiming or Advertising: Campaign Finance and the Source of the Personal Vote in Brazil. The Journal of Politics, 64(3), p. 845-863, 2002.

SEN, A. Desenvolvimento como liberdade. São Paulo: Companhia das Letras, 2000.

SPECK, B. W. Como financiar a competição política? Concepções contemporâneas, ilustrações do caso da Alemanha e perspectivas para a situação no Uruguay. In: CAETANO, G. et al. Dinero y Política. El Financiamiento de los Partidos en la Democracia. Montevideo: Ediciones de La Banda Oriental, 2002.

SPECK, B. W. Reagir a escândalos ou perseguir ideais? A regulação do financiamento político no Brasil. Cadernos Adenauer. Rio de Janeiro, ano VI, n. 2, p. 123-159, 2005.

SPECK, B. W.; MANCUSO, W. P. Financiamento, capital político e gênero: um estudo de determinantes do desempenho eleitoral nas eleições legislativas brasileiras de 2010. Trabalho apresentado ao 36o ENCONTRO ANUAL DA ANPOCS. Águas de Lindóia, SP, 2012.

TSE, Repositório de dados eleitorais em http://www.tse.jus.br/eleicoes/estatisticas/repositorio-dedados-eleitorais. Data de acesso: 08/03/2015

ZOVATTO, D. Financiamento dos partidos e campanhas eleitorais na América Latina: uma análise comparada. Opinião Pública. Campinas, vol. XI, n. 2, p. 287- 336, out., 2005.

Artigo recebido em 28/09/2017. Aceito para publicação em 16/11/2018. 